\title{
A Trial Exploration of Cultural Creativity and Communication of Film and Television Art
}

\author{
YU Ruihua \\ College of Media and Communication, Zaozhuang University \\ P.R.China 277100 \\ E-mail: yrh621010@163.com
}

\begin{abstract}
Culture needs creativity, and cultural communication needs media. As the most superior carriers, film and television are endowed with cultural exchanges. This paper mainly studies the global situation of current cultural creativity and film arts communication. By analyzing the existing differences between Chinese and Western cultures, this paper describes the relationship between cultural communication and film arts communication, analyzes the global influence of cultural creativity in other countries and the influence of domestic film and television art works in the whole world. At last, this paper puts forward the corresponding suggestions on the cultural creativity and film arts communication.
\end{abstract}

Keywords-Cultural creativity; Film and television art; Communication

\section{INTRODUCTION}

Nowadays, the pursuit of box office of Film and TV art is becoming higher and higher. Both films and TV dramas need a lot of cultural infiltration of new creativity. Culture is inseparable from creativity, and creativity needs culture as a carrier. As a carrier of cultural communication, how to combine cultural creativity with film and TV art, further the cultural inheritance and globalize the culture is a problem we need to consider now. Therefore, to create and communicate our culture, we should make a scientific combination of culture and film and television art, complement each other and develop them together, to form a more contemporary and more humane communication culture in the process of cultural communication. The introduction of cultural creativity has a definite conclusion on cultural creativity. The book shows that "The connotation of cultural creativity is mainly derived from the connotation of cultural and creative industries". "The expression of cultural creativity is the cultural and creative industry. The achievement of cultural creativity is the cultural and creative industry. Cultural and creative industries need certain cultural ideas to serve them." The essence of things is their fundamental nature, and the special contradictions of things constitute the essence of things and exist in the internal structure. The unity of their values is the unity of the internal structure and external functions and functions of things. To achieve this, how to grasp the communication of film and television art, as well as the combination of film and television communication and art, and promote the spread of culture, has become the top issue of film and television communication.

\section{THE CURRENT SituATION AND IMPORTANCE OF CUlTuRAl CREATIVITY}

In the academic field, cultural creativity is a cultural achievement which is reproduced and innovated by utilizing related disciplines and different carriers and integrating into multiculturalism based on culture as a factor. The popular talk is to innovate in the scope of culture. The core of cultural creativity is to improve the creativity of human beings and to give full play to the greatest creativity of the people. "Creativity" contains two aspects. The first is the so-called "original". That is to say, this thing is not created by predecessors or others. It is entirely created by people themselves, such as the Chinese original: Peking Opera and martial arts. The second is "innovation", which means that though this kind of thing is created by others first, we will further transform it to form a new thing, which will give others a new feeling. The famous movie "Crouching Tiger, Hidden Dragon", which is a blend of eastern and western cultures and the western art contains Chinese culture, giving a stretch of a new feeling, is a process of innovation rather than the original.

Lu Xun once said that "literature and art are the light of the national spirit". Unfortunately, in recent years, the "light beam" become bleak: in the process of literary and artistic creation, a large part of the theme of is similar and copied, and vulgar culture appears. The creativity of literary works is not enough. Ninety percent of the works are copies. On television, a large part of the old theme and subversion of the classic works are remade. The so-called copycat works, copy the original mode, do not change the core, make only superficial changes. A state of depression appears from the current situation of the outline of literary works.

Cultural creativity brings the development of cultural industry, and cultural industry also needs creativity. In cultural industry, excellent creativity can break through interference and attract people's attention. If we want to turn culture into economic benefit, we must make this thing to be recognized, liked and accepted, and pay enough attention to it. With the development of science and technology and the trend of economic globalization is gradually strengthened, cultural creativity in the global cultural development occupies an increasingly important position. China, as a big country in the world, it needs to show its country's style. Culture is the core 
of a country's soft power, so we should accelerate the development of local cultural creative industries. Chinese culture is increasingly recognized and respected in other countries in the world.

\section{The CONNOTATION AND Global Status Of FILM AND TELEVISION ART COMMUNICATION}

Through the corresponding material media and the way of communication, the process of transferring the works to others is the communication of art, which also means the flow of art information in the society. The art of film and television is the greatest invention of human in the twentieth century. Today, film and television art is no longer a simple means of communication, but a form of art that can give people a visual shock and make people's heart and heart blend with each other. With the rapid development of the Internet, the demand for economic interests and social life is becoming higher and higher, and it has further promoted the development of the art of film and television. Film and television art, if it wants to attract the audience's eyeballs and win in a large number of art, it must be innovative and the quality of the film must be improved.

Currently, the development of foreign film theory is more perfect, and China started late in this field. Compared with foreign countries, there is still big gap to be caught up. There is a phenomenon that the researchers directly use foreign film theories to study the domestic film and television art, to solve the elegance and vulgarity problems in domestic film theory study, and even expect to develop its own film art in China. The contemporary film and TV art creation must adhere to the "people-oriented" aesthetic ideal to determine its own development orientation. Globalization is a new trend in the development of today's era. There are more closely related aspects in politics, economy, culture, ideology and management all over the world, and at the same time, there are some new visages in the art of film and television. First of all, the production and distribution of the national film and television works tend to globalization, Nowadays, economy and culture exchange more closely. On this basis, the art of film and television works is widely spread more rapidly, into the international market. Correspondingly, the world will share the film production technology, and bring more technology to the world developing countries. Secondly, people from different countries can see different countries' film and television works. Through this media, they can understand the cultural connotations of different countries, and promote the spread of their own culture in the world. Thirdly, compared to the film and television works in some developing countries, the developed countries' works is more outstanding. Some developing countries have low income on the economic benefits, and developed countries gain more benefits from their film and television works relying on their own economic strength advantage, strongly flow in the world. It will cause the cultural exchange "deficit" in the developing countries in the world, and bring serious threat to the cultural exchange of these countries.
In short, under the background of globalization, film and television art, as a most direct cultural communication medium, needs to interact with the world positively, keep pace with the times, constantly expand its own strength, innovate itself, and maintain its own national cultural characteristics.

\section{The Mutual DifFerence Between Chinese And WESTERN CULTURE}

Because of the different geographical location and culture, the world can be divided into two eastern and western regions, which also lead to their cultural differences. The specific reasons can be divided into two aspects.

\section{Economic system}

The traditional economy of China is mainly self sufficient and natural economy. People are more conservative, so their culture is more introverted. And the ancient civilization of China belongs to the agricultural civilization, which makes the Orientals pay much attention to the ethics and morality and maintain the traditional ideas. The western ancient Greek civilization belongs to the marine civilization, so the westerners prefer to explore, and their culture is more extroverted. Moreover, the western countries entered the industrial economic era very early because of the industrial revolution, and at the same time, they also created Westerners' strong fighting spirit and legal consciousness, taking independence, freedom and equality as the principles of life.

\section{Geographical environment}

Because the continental geographical environment is more closed, the Chinese people are more limited in thinking. This thinking leads to the Chinese static stability, and not competing for everything, peace loving, lack of curiosity for new things. While the western countries in the marine geographical environment is more open, with more developed maritime industry and commerce. At the same time, the turbulent ocean environment forms the Westerners' actively aggressive personality.

Japan regards enhancing cultural competitiveness as an important measure to enhance the competitiveness of Japanese products. It believes that through cultural products, the understanding of Japanese culture can be deepened, and Japan can be respected in the international status. They constantly strengthen their innovation of their cultural products, and strive to meet the needs of the new era. Japan's cultural industry is mainly divided into manufacturing, leisure industry and fashion industry.

The cultural connotation of each country is different because of the different degree of economic development and the development of regional culture. A thorough comparative study of the cultural concepts of different countries will help us to recognize their strengths and weaknesses, so as to give full play to their strengths so as to promote the harmonious development of China's economic culture. 


\section{THE INTERRELATION BETWEEN CULTURAL COMMUNICATION AND ART COMMUNICATION}

Cultural communication is very important in the film and television art. In today's society, the mass culture industry works in the premise to follow the laws of the market under the mode of production. Because of the spread of mass media, the urban and rural public consumption has become the object, and the nature of western traditional culture gradually changed Independence, freedom and critical spirit of the western culture has gradually been commercialized after the advent of the industrial era. It becomes a cultural industry, integrated with society, making social reflection and critical force. Viewing film and TV as a culture is far beyond the scope of art. We need to take care of it from the perspective of philosophy and culture, so that we can have a deep understanding of film culture.

As a universal social and cultural phenomenon, film and TV can reflect the information of the times and the society, and reflect the change of times and the change of social consciousness. In the era of economic globalization, culture has begun to communicate with other countries rapidly. In fact, cultural communication and communication among different countries have become the main form of current art communication and has become a necessary means of diplomacy between countries. Among the many art forms, the film has the most superior ability to spread. The transmission ability of the movie is very strong, and different from other art forms which have various limitations. The visual effect of the movie can be circulated quickly in the whole world, and no matter what kind of movie, it can achieve better communication effect on the basis of vision. Therefore, the film has also become an important carrier of cultural communication.

As we all know, for a long time, Chinese film lacks a broad international vision and has been in a passive state. This situation lasted until the 80 s of last century, but Chinese movie still has a long way to go into the international market. Today, under the background of globalization, it is necessary for Chinese movie to have more cultural exchanges with other countries. As the name implies, cultural communication should include culture and communication, the two can not be separated. The essence of communication is cultural exchanges, while cultural exchanges also needs communication.

For Chinese film, some film appeared in the 80s ,90s of last century, such as "Red Sorghum", "Red Lantern", "the Yellow River Ballad", "Red" and "Temptress Moon" is the earliest batch of film works which successfully push the Chinese film to the world, and made the Chinese film win a position in the world. The film "Crouching Tiger, Hidden Dragon" successfully created a record for the longest on-line Chinese film in Western cinema. The film "Hero", directed by Zhang Yimou is an important breakthrough in Chinese film to enter the overseas market. The plot of "Crouching Tiger, Hidden Dragon" is slightly similar with the texture of the foreign film "Inside the Matrix" which made the western audience has a similar feeling, as the China "Liang Shanbo and Zhu Yingtai" is known as the western "Romeo and Juliet".

\section{IMPROVING CULTURAL CREATIVITY AND DEEPENING THE COMMUNICATION OF FILM AND TELEVISION ART}

The dissemination, survival and development of any culture can not be separated from a form. A good form will be loved by people, and will also be unconsciously accepted by people in the process of communication. Cultural form innovation will enhance people's attention to culture. People from different nationalities and different levels need different cultures. Strengthening cultural form innovation will be acceptable to all kinds of people. What's more, in the form of cultural communication, we should combine the traditional and the modern, the national and the international, and good culture should be combined with the time. Otherwise, traditional culture will not have fresh vitality, nor can it reflect a country's cultural soft power. The spread of film and television art is very conductive to the public. If we want to make the film and TV transmission more profound, we must strengthen the artistic atmosphere of film and television works, make the public more able to accept it, appreciate it, and film and television works can shine brilliantly on the international stage.

\section{CONCLUSION}

In summary, cultural creativity and film and TV art communication is closely related. As long as we combine the creation and dissemination of culture with film and television works, complement it with film and TV art, grasp the cultural creative communication in the right direction and try to realize cultural innovation correctly and scientifically, we can achieve a more contemporary culture that can make our own culture shine in the international arena for film and TV art. At the same time, we should continue to strengthen the integration of Chinese and Western cultures for film and TV art communication, create film and television works with great care and put the excellent culture in the works of different countries into the core of our works. Therefore, our works can be accepted by different people can accept and actively occupy the international market

\section{REFERENCES}

[1] Xin Yubin. Analysis of the artistic features of micro propagation under the background of film and television art [J]. Chizi (MID), 2017 (05): 80. (In Chinese)

[2] Zhou Kaiya. Analysis of micro propagation problems about film and television art [J]. Art Technology, 2016, 29 (03): 124. (In Chinese)

[3] Xu Bin. Research on the micro communication of film and television art [D]. Jiangsu Normal University, 2013.(In Chinese)

[4] Xu Rui. Research on the creative performance of digital film and television works [D]. Zhejiang Agroforestry University, 2011.(In Chinese)

[5] Xu Zhangjie. Discussion on the formal aesthetic of modern film and television advertising [J]. Theory Monthly, 2009, (01): 85-87. (In Chinese) 